Article

\title{
Attention-Deficit/Hyperactivity Disorder Symptoms, Sensation-Seeking, and Sensory Modulation Dysfunction in Substance Use Disorder: A Cross Sectional Two-Group Comparative Study
}

\author{
Naama Assayag ${ }^{1}$, Itai Berger ${ }^{2,3}$, Shula Parush ${ }^{1}$, Haim Mell ${ }^{4}$ and Tami Bar-Shalita ${ }^{5, *(D)}$ \\ 1 School of Occupational Therapy, Faculty of Medicine, Hebrew University of Jerusalem, \\ Jerusalem 9112102, Israel; naama.lasri@mail.huji.ac.il (N.A.); shula.parush@mail.huji.ac.il (S.P.) \\ 2 Pediatric Neurology, Pediatric Division, Assuta Ashdod University Hospital, Faculty of Health Sciences, \\ Ben-Gurion University, Beer-Sheva 8443944, Israel; dr.itai.berger@gmail.com \\ 3 School of Social Work and Social Welfare, Hebrew University of Jerusalem, Jerusalem 9190501, Israel \\ 4 Department of Criminology, Max Stern Yezreel Valley College, Yezreel Valley 1930600, Israel; \\ mellhaim@012.net.il \\ 5 Department of Occupational Therapy, School of Health Professions, Faculty of Medicine, Tel Aviv University, \\ Tel Aviv 6997801, Israel \\ * Correspondence: tbshalita@post.tau.ac.il
}

check for updates

Citation: Assayag, N.; Berger, I.; Parush, S.; Mell, H.; Bar-Shalita, T. Attention-Deficit/Hyperactivity Disorder Symptoms, SensationSeeking, and Sensory Modulation Dysfunction in Substance Use Disorder: A Cross Sectional Two-Group Comparative Study. Int. J. Environ. Res. Public Health 2022, 19, 2541. https://doi.org/10.3390/ ijerph19052541

Academic Editor: Paul B. Tchounwou

Received: 23 January 2022 Accepted: 14 February 2022 Published: 22 February 2022

Publisher's Note: MDPI stays neutral with regard to jurisdictional claims in published maps and institutional affiliations.

Copyright: (c) 2022 by the authors Licensee MDPI, Basel, Switzerland. This article is an open access article distributed under the terms and conditions of the Creative Commons Attribution (CC BY) license (https:// creativecommons.org/licenses/by/ $4.0 /)$.

\begin{abstract}
Background: Attention-deficit/hyperactivity disorder (ADHD) and sensation-seeking, a trait characterized by risk-related behaviors, have been recognized as risk factors in substance use disorder (SUD). Though ADHD co-occurs with sensory modulation dysfunction (SMD), SMD has scarcely been explored in SUD. Thus, this study aimed to characterize ADHD symptomology, sensation-seeking, and SMD, as well as to explore their contribution to SUD likelihood. Methods: A cross sectional two-group comparative study including therapeutic community residents with SUD ( $n=58$; study group) and healthy individuals ( $n=62$; comparison group) applying the MOXO continuous performance test (MOXO-CPT) evaluating ADHD-related symptoms. In addition, participants completed the ADHD Self-Report Scale-Version 1.1 for ADHD screening; the Brief Sensation Seeking Scale quantifying risk-taking behaviors; and the Sensory Responsiveness Questionnaire-Intensity Scale for identifying SMD. Results: The study group demonstrated higher SMD incidence (53.57\% vs. $14.52 \%$ ) and lower performance in three MOXO-CPT indexes: Attention, Impulsivity, and Hyperactivity, but not in Timing, compared to the comparison group. Sensory over-responsiveness had the strongest relationship with SUD, indicating 27-times increased odds for SUD (95\% CI = 5.965, 121.216; $p \leq 0.0001)$. A probability risk index is proposed. Conclusion: We found SMD with the strongest relation to SUD exceeding that of ADHD, thus contributing a new perspective for developing future therapeutic modalities. Our findings highlight the need to address SMD above and beyond ADHD symptomology throughout the SUD rehabilitation.
\end{abstract}

Keywords: SUD; ADHD; sensation-seeking; sensory processing; sensory over-responsiveness; risk factor; therapeutic community

\section{Introduction}

The bidirectional link of substance use disorder (SUD) and attention-deficit/hyperactivity disorder (ADHD) is widely described [1-4], although its nature remains unclear [5]. ADHD, a neurodevelopmental disorder characterized by inattentive or hyperactive/impulsive behavior, or both [6], is associated with impairment in multiple life domains [7-9]. A meta-analysis found that $23.1 \%$ of those seeking SUD treatment have ADHD [10]. Moreover, ADHD has been reported as a risk factor for SUD [11,12]. Interestingly, ADHD is related to traits such as sensation-seeking [13], included under the broader umbrella of 
disinhibition [14], characterized by the desire for intense and novel experiences [15], and considered a trait of risk-taking behavior [16]. Sensation-seeking has consistently been related to higher incidences of alcohol and substance abuse $[17,18]$, recognized as a risk factor for adolescent substance use [14,18], and for the development and maintenance of SUD. ADHD has also been found as an independent predictor of sensation-seeking [19].

Recent years have provided a sound base of evidence regarding the co-occurrence of ADHD and sensory modulation dysfunction (SMD) [20-23]. SMD is a neurodevelopmental sensory-processing alteration, characterized by difficulty in regulating the degree, nature, or intensity of responses to sensory stimulation in single or multiple sensory systems [24-26]. Its clinical manifestations are characterized by sensory under-responsivity (SMD-SUR), demonstrated by disregarded or delayed responses to stimulation; and sensory overresponsivity (SMD-SOR), perceiving non-painful sensations as irritating, unpleasant [25,27], or painful [28-30]. The sensory realm has been neglected over the years [31], and only recently, initial findings indicate SMD in SUD [32-36]. Importantly, our recent work found that $54 \%$ of individuals with SUD were also identified as having SMD; specifically, $47 \%$ were identified with SMD-SOR [32]. Evidence supports ADHD and SMD as distinct conditions, e.g., $[20,21,37]$, yet the differential diagnosis between SMD and ADHD is often challenging, due to the overlapping symptoms and high rate of co-morbidities [37].

As far as we know, the co-occurrence of ADHD and SMD has not yet been explored among individuals with SUD, leaving the contribution of SMD, as well as its distinct profile in the SUD phenomenon, empirically sparse. Further, since SMD severely interferes with participation in everyday activities [38,39], and impacts quality of life [28,40], exploring the contribution of SMD, beyond and above ADHD and sensation-seeking symptomology, can deepen the understanding of the risks and trajectories for one of the most global health concerns, and, in the future, may add a new therapeutic modality for individuals with SUD.

Therefore, the aims of this study were to characterize attention-deficit/hyperactivity disorder symptomology, sensation-seeking, and SMD among therapeutic community residents with SUD, and to examine each contribution to SUD likelihood.

\section{Materials and Methods}

This research has been approved by the Institutional Ethical Review Committee Board (IRB), Tel Aviv University (11002976_20160720). All participants were informed of the research objectives and possible inconveniences, and signed an informed consent.

\subsection{Study Design}

This was a cross sectional two-group comparative study.

\subsection{Participants}

The study group comprised individuals aged 18-54 years, residing in a therapeutic community (TC) in northern Israel. All of the TC residents meet the diagnostic criteria for severe SUD according to the Diagnostic and Statistical Manual of Mental Disorders-IV (DSM-IV) [6], and had no dual diagnosis and no cognitive deficits. The TC is a rehabilitation center providing a controlled drug-free environment with multidimensional support [41,42], lasting typically 1 to 1.5 years. Abstinence is routinely verified through random urine testing. The comparison group, age-matched, was composed of recruited healthy volunteers from the general population, using the snow-ball sampling method.

For the study group, inclusion criteria stipulated no current use of medication for psychological or neurological disorders; no known brain lesions; adequate language skills; and abstinence from drugs and alcohol for at least 14 days. All individuals in the TC meeting the inclusion criteria participated in the study, comprising the study group. This purposive sample method [43] effectively negated the potential for volunteer bias. 
For the comparison group, inclusion criteria were current or past drug and alcohol abuse; past or present neurological, neurodevelopmental, or psychiatric diagnosis, including ADHD according to self-reporting.

Sample size was based on a study which compared sensory modulation types between people with SUD and healthy people [33]. Calculation was based on power analyses derived from a $p$ value of 0.05 and a statistical power of 0.80 , yielding $n=58$ in each group.

\subsection{Assessments}

\subsubsection{Performance Testing}

The MOXO Continuous Performance Test (MOXO-CPT) [44] was utilized: a standardized, computerized 18.2-min test to diagnose ADHD-related symptoms [45], using target and non-target card images comprising eight blocks (136.5 s, 59 trials each).

In each trial, the target is presented in the middle of a computer screen for 500, 1000, or $3000 \mathrm{~ms}$, followed by a 'void' period of the same duration. Distractor onset is not synchronized with target onset, and could be presented during the void period as well.

Distractors are presented for $8 \mathrm{~s}$, with a fixed interval of $0.5 \mathrm{~s}$ between two distractors. Participants are requested to respond to the target stimuli as fast as possible by pressing the space bar only once, and avoid responding to non-target stimuli. Three types of distractions are presented: (a) visual distractors (e.g., animated barking dog); (b) auditory distractors (e.g., barking sound); and (c) a combination of both (e.g., animated barking dog with the sound of barking). Visual distractors appear at one of four spatial locations on the sides of the screen: down, up, left, or right. Overall, eight different distractors were included, and each of them could appear as purely visual, purely auditory, or as a combination of them. The MOXO-CPT provides four indexes: (a) Attention-the number of correct responses to targets not bound by any time frame (max. score 272); (b) Timing - the number of correct responses only while targets are presented (max. score 272); (c) Impulsivity-the number of impulsive responses to non-target stimuli; and (d) Hyperactivity - the remaining commission errors not counted as impulsivity (for example, multiple spacebar presses or random key pressing) (Figure 1).
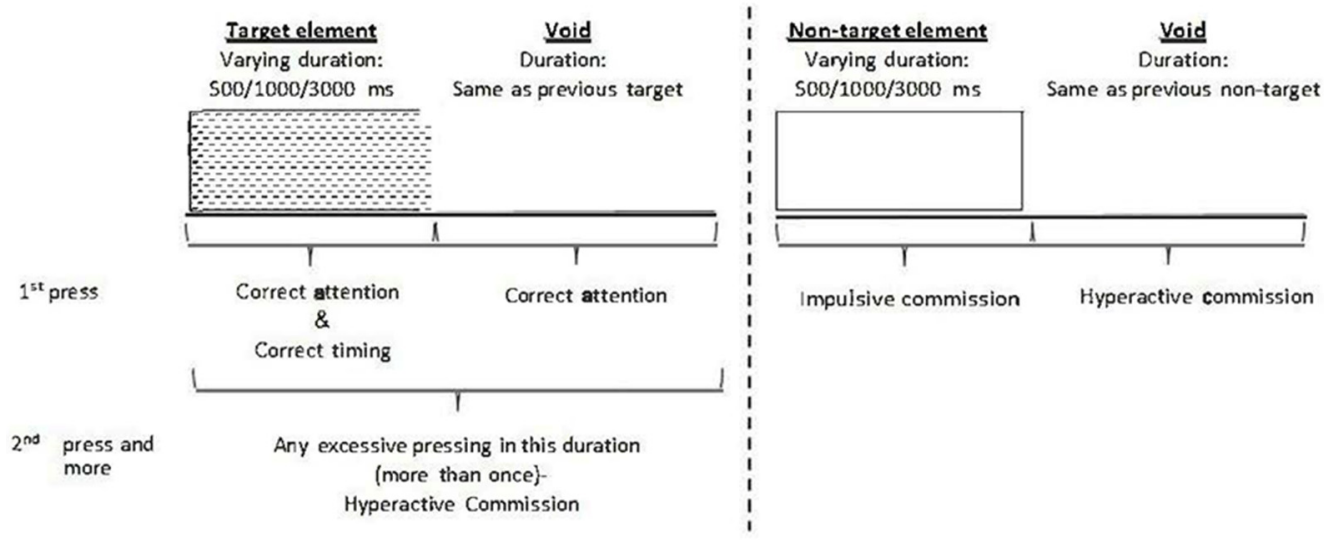

Figure 1. MOXO-CPT description. MOXO-CPT, MOXO continuous performance test; ms, milliseconds. Definition of the timeline, target, and non-target stimuli were presented for 500, 1000, or $3000 \mathrm{~ms}$. Each stimulus was followed by a void period of the same duration. The stimulus remained on screen for the full duration regardless of the response. Distracting stimuli were not synchronized with target/non-target onset, and could be generated during target/non target stimulus or during the void period.

\subsubsection{Self-Report Questionnaires}

The Adult ADHD Self-Report Scale-Version 1.1 (ASRS-V1.1) [46] was utilized: a standardized, reliable, and valid 18-item checklist for evaluating adult ADHD based on the DSM-IV diagnostic criteria. Our study utilized the shortened 6-item version on a 5-point Likert scale ('Never' (0) to 'Very Often' (4)), which reported high agreement with 
the clinical classification of adult ADHD [47], and has proven beneficial for screening the SUD population [48]. Using the recent adaptation for the ASRS scoring based on Ustun et al. (2017) [49], we applied the score of 11 as the cut-off point. A high internal consistency (Cronbach's alpha 0.88 [50]), and good test-retest reliability were reported [51]. The 6-item version has a moderate sensitivity of $68.7 \%$ and a high specificity of $99.5 \%$ [46]. In this study, the ASRS was completed only by the SUD group.

The Brief Sensation Seeking Scale (BSSS) [17] was utilized: a standardized, reliable, and valid 8-item self-report scale measuring sensation-seeking through four dimensions: experience-seeking; boredom susceptibility; thrill- and adventure-seeking; and disinhibition. Responses are indicated on a 5-point Likert scale from 'strongly disagree' (1) to 'strongly agree' (5). The BSSS has high internal consistency (Cronbach's alpha 0.76), and solid psychometric characteristics with stability across age, gender, and ethnic categories.

The Sensory Responsiveness Questionnaire-Intensity Scale (SRQ-IS) [52] was utilized: a standardized, reliable, and valid 58-item scale for identifying SMD. It presents routine activities involving one sensory stimulus in one modality (auditory, visual, gustatory, olfactory, vestibular, and somatosensory, excluding pain). Participants are requested to rate their response on a 5-point Likert scale from 'not at all' (1) to 'very much' (5). The SRQ provides two scores for each of the two SMD subtypes: SMD-SOR is determined by applying the SRQ-Aversive subscale score for scores higher than the normal cut-off score (mean + 2SD; $1.87+0.52$ ); the SMD-SUR subtype is determined by applying the SRQ-Hedonic subscale score for scores higher than the normal cut-off score (mean + 2SD; $2.10+0.66$ ). High internal consistency (Cronbach $\alpha=0.90-0.93$ ), test-retest reliability $(\mathrm{r}=0.71-0.84, p<0.01-0.05)$, content, criterion, and construct validity were reported [52].

\subsection{Procedures}

Both groups completed the questionnaires and the MOXO-CPT during one-hour sessions. All data were collected by one researcher (N.A.) in an air-conditioned $\left(22-24^{\circ} \mathrm{C}\right)$ room, with ambient noise typically not exceeding 45dBSPL.

\subsection{Data Analysis}

Statistical analyses were performed with SAS V9.4 (SAS Institute, Cary, NC, USA). Descriptive statistics (mean, standard deviation, minimum, median and maximum for continuous variables, and a count and percentage for discrete variables) are presented for the study parameters by research group (study/comparison). Categorical variables were compared between the two groups using a chi-squared test, and the continuous variables with a two-sample $t$-test.

SUD was modeled using logistic regression, and SMD-SOR/non-SMD-SOR status, SMD-SUR/non-SMD-SUR status, MOXO-CPT four indexes, and BSSS-Total score were entered as potential risk factors. Odds ratios ( $95 \%$ confidence intervals) were presented, and significant variables $(p<0.05)$ were entered into a multivariate model. The variables that remained in the model were those which remained statistically significant when entered together, and maximized the predictive power (area under the curve (AUC) of the receiver operating characteristic (ROC) curve) of the model, such that the AUC of the resulting ROC curve was at least 0.8 . The risk score, which was calculated from a linear combination of the logistic regression model coefficients, is presented in an effect plot portraying the risk of having SUD as a function of the SMD sub-type, MOXO-CPT indexes, and BSSS-Total score. All statistical tests were two-sided. A $p$-value of 0.05 or lower was considered statistically significant. No adjustments for multiple testing were performed, as this is a report of a preliminary examination of these associations; thus, only nominal $p$-values are presented.

\section{Results}

\subsection{Demographic Characteristics}

One hundred and twenty individuals $(89 \%$ men $(n=107))$, mean (SD) age $26.7(8.08)$, divided into the study (SUD, $n=58$ ) and comparison (healthy, $n=62$ ) groups, participated in 
this study. Within the study group, 33\% of participants screened positive for ADHD. No statistically significant group differences were found with respect to $\operatorname{sex}\left(\chi^{2}(1, N=120)=0.57\right.$, $p=0.4507)$ or age $(t(91)=0.89, p=0.3776)$. Formal education (years) was found to be significantly different $(t(98)=-7.35, p<0.0001)$, revealing fewer years of education in the study group (Table 1).

Table 1. Gender, age, and years of education distribution in the two groups, and substance use divided into categories in the study group.

\begin{tabular}{lcc}
\hline \multicolumn{1}{c}{ Charactristics } & $\begin{array}{c}\text { Study Group } \\
\boldsymbol{n}=\mathbf{5 8}\end{array}$ & $\begin{array}{c}\text { Comparison Group } \\
\boldsymbol{n}=\mathbf{6 2}\end{array}$ \\
\hline Gender & $91.4 \%(n=53)$ & $87.1 \%(n=54)$ \\
Male & $8.6 \%(n=5)$ & $12.9 \%(n=8)$ \\
Female & $27.4(9.94)$ & $26.0(5.83)$ \\
Age (years), Mean (SD) & $11.4(1.30)$ & $13.9(2.27)$ \\
Years of education, Mean (SD) & & \\
Substance use distribution * & $22.4 \%(n=13)$ & \\
Cannabis & $22.4 \%(n=13)$ & \\
Opioids & $8.6 \%(n=5)$ & \\
Stimulants & $31 \%(n=18)$ & \\
Synthetic cannabinoid & $15.5 \%(n=9)$ & \\
Alcohol & $16.4(3.78)$ & \\
Initial age for drug use, Mean (SD) & & \\
* Substance use distribution according to preferred psychoactive substance in the study group. SD, standard \\
deviation.
\end{tabular}

\subsection{Substance Use Consumption in the Study Group}

Substances were divided into five categories [53] based on self-reported preferred psychoactive substance: Cannabis, Opioids, Stimulants, Synthetic Cannabinoid, and Alcohol. The most-reported past consumed substance in the study group was Synthetic Cannabinoid, whereas the least consumed were Stimulants (Table 1).

\subsection{Group Differences in the MOXO-CPT Indexes}

Significant group differences were found in the three MOXO-CPT indexes: Attention, Impulsivity, and Hyperactivity $(t(97)=-3.42, p=0.0009 ; t(97)=3.83, p=0.0002 ; t(97)=3.81$, $p=0.0002$ ), but not in Timing (Table 2 ).

Table 2. Distribution of SMD (\% (n)), BSSS, and MOXO-CPT indexes (mean (SD)) in both groups.

\begin{tabular}{lcc}
\hline \multicolumn{1}{c}{ Study Variables } & $\begin{array}{c}\text { Study Group } \\
(\boldsymbol{n}=\mathbf{5 8 )}\end{array}$ & $\begin{array}{c}\text { Comparison Group } \\
(\boldsymbol{n}=\mathbf{6 2})\end{array}$ \\
\hline SMD & $53.6(30)$ & $14.5(9)$ \\
SMD-SUR & $14.3(8)$ & $6.5(4)$ \\
SMD-SOR & $48.2(27)$ & $8 / 1(5)$ \\
BSSS-Total score & $3.5(0.73)$ & $2.8(0.75)$ \\
Experience-Seeking & $3.6(1.00)$ & $3.4(1.03)$ \\
Boredom Susceptibility & $3.1(0.74)$ & $2.5(0.90)$ \\
Thrill- and Adventure-Seeking & $3.6(1.19)$ & $2.7(0.98)$ \\
MOXO-CPT * & & \\
Disinhibition & $3.7(1.09)$ & $2.5(1.09)$ \\
Attention & $265.1(9.55)$ & $269.6(2.61)$ \\
Timing & $232.9(25.27)$ & $233.4(24.31)$ \\
Hyperactivity & $9.4(11.96)$ & $3.2(2.79)$ \\
Impulsivity & $17.7(13.53)$ & $9.7(6.95)$ \\
\hline
\end{tabular}

SMD, sensory modulation dysfunction; SMD-SUR, sensory under-responsivity; SMD-SOR, sensory overresponsivity; BSSS, Brief Sensation Seeking Scale; SD, standard deviations (higher scores (range 1-5) denote higher levels of sensation-seeking); $\mathrm{MOXO}-\mathrm{CPT}$, MOXO continuous performance test; for Attention and Timing indexes (max. score 272), higher scores denote better performance. For Hyperactivity and Impulsivity indexes (min. score 0 ), lower scores denote better performance; ${ }^{*}$ Moxo $n$ in the study group $=42$. 


\subsection{Group Differences in the BSSS Dimensions}

Statistically significant group differences were found in the BSSS-Total score and in the three BSSS dimensions: Boredom Susceptibility; Thrill- and Adventure-Seeking; and Disinhibition $((t(110)=5.23, p<0.0001) ; t(110)=3.61, p=0.0005 ; t(110)=4.42, p<0.0001$; $t(110)=5.97, p<0.0001$, respectively) (Table 2$)$.

\subsection{SMD Distribution in the Study and Comparison Groups}

A statistically significant group difference was found in the SMD incidence, demonstrating a higher rate in the study group (53.57\%) comprising mostly SMD-SOR vs. the comparison group (14.52\%) (SMD: $\chi^{2}(1)=20.28, p<0.0001$; SMD-SOR: $\chi^{2}(1)=23.99$, $p<0.0001$ ) (Table 2). No statistically significant group difference was found in SMD-SUR incidence $\left(\chi^{2}(1)=1.98 ; p=0.16\right)$ (Table 2$)$. Statistically significant group differences were also found in both SRQ scores, showing elevated scores in the study group: (SRQ-Aversive mean (SD): study group: 2.3 (0.52) vs. comparison group: $1.9(0.30), t(116)=5.15, p<0.0001$; and SRQ-Hedonic mean (SD): study group: 2.3 (0.43) vs. comparison group: 2.06 (0.36), $t(116)=3.53, p=0.0006)$.

\subsection{SMD, MOXO-CPT, and Sensation-Seeking as Risk Factors for SUD}

SMD-SOR (Yes/No), MOXO-CPT Impulsivity Index, and BSSS-Total score were found to be significantly related to SUD in a multivariate model and in ROC analysis, by maximizing the area under the curve (AUC). The additional variables of the MOXO-CPT Impulsivity Index and the BSSS-Total score significantly improved the AUC of the test, reaching 0.904 (95\% Wald CI: (0.8431-0.9658)) versus the model with SMD-SOR alone (AUC $=0.7281$; 95\% Wald CI: (0.6409-0.8152)). Table 3 presents the adjusted odds ratios, 95\% confidence intervals, and levels of significance. SMD-SOR was found to be the strongest risk factor for SUD: subjects with SMD-SOR were found to be at 26.889-times higher risk than subjects without SMD-SOR (Table 3).

Table 3. The likelihood for SUD by Sensory Over-Responsivity, MOXO-CPT Impulsivity, and Sensation-Seeking.

\begin{tabular}{lcccc}
\hline \multicolumn{1}{c}{ Variable } & OR & Lower 95\% CI & Upper 95\% CI & Pr > ChiSq \\
\hline SMD-SOR (Yes/No) & 26.889 & 5.965 & 121.216 & $<0.0001$ \\
MOXO-CPT Impulsivity Index & 1.136 & 1.056 & 1.222 & 0.0006 \\
BSSS-Total score & 2.877 & 2.877 & 6.455 & 0.0103 \\
\hline
\end{tabular}

SUD, substance use disorder; OR, odds ratio; 95\% CI, 95\% confidence interval; SMD-SOR, sensory overresponsivity; SMD-SUR, sensory under-responsivity; MOXO-CPT, MOXO continuous performance test; BSSS, Brief Sensation Seeking Scale.

The logistic regression model coefficients were used to derive a probability index as $P=e Y /(1+e Y)$, where $Y$ is a linear combination of the model coefficients. The probability index is presented on a scale of 0 to 1 , where a higher score indicates a higher likelihood for having SUD. Figure 2 demonstrates the predicted SUD probability score value for individuals with and without SMD-SOR, based on their BSSS-Total score and MOXO-CPT Impulsivity Index. Whereas the probability index score for SUD for a person without SMD-SOR with a BSSS Total score of 3 and a MOXO-CPT Impulsivity score of 20 is about $0.20(20 \%)$, the probability for someone with the same scores who also has SMD-SOR escalates to nearly $0.80(80 \%)$. 


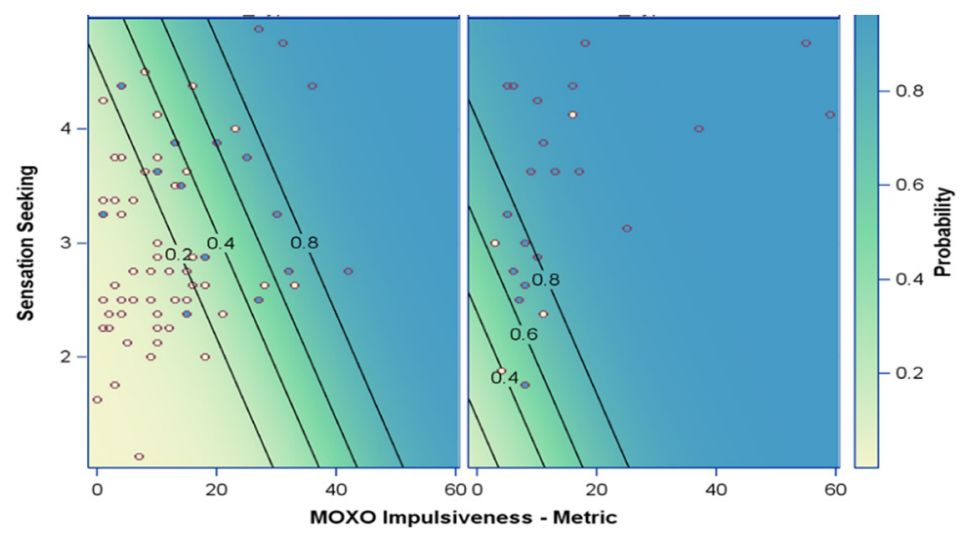

Figure 2. Risk index for SUD. The probability index for SUD takes into account the BSSS-Total score and the MOXO-CPT Impulsivity Index, differentiating between persons with and without SMD-SOR. SMD-SOR, sensory over-responsivity; MOXO-CPT, MOXO continuous performance test; SUD, substance use disorder.

\section{Discussion}

The aims of this study were to characterize attention-deficit/hyperactivity disorder symptomology, sensation-seeking, and sensory modulation dysfunction among TC residents with substance use disorder, and to examine each contribution to substance use disorder likelihood. Although each of the variables separately was previously reported in the SUD population $[19,32,54]$, to the best of our knowledge, this is the first study to examine the interplay between ADHD symptomology, sensation-seeking and SMD in individuals with SUD residing in a TC. The study group displayed higher incidence of SMD- and ADHD-related symptoms compared to the comparison group. Though ADHD is a known risk factor for SUD, our data suggests that SMD-SOR has a higher incidence and a stronger link to SUD compared to ADHD.

This study found an ADHD prevalence of 33\%, closely approximating ADHD in SUDreported prevalence [48]. Though most studies examined ADHD symptoms as a group or according to the diagnosis subtypes (mainly inattentive, mainly hyperactive/impulsive, or combined type) [55,56], this current study quantified each ADHD symptom independently using the MOXO-CPT (e.g., Attention, Timing, Impulsivity, and Hyperactivity), and found that the SUD group demonstrated lower performance in three MOXO-CPT indexes: Attention, Impulsivity, and Hyperactivity. Our results are in line with previous research showing that the MOXO-CPT distinguished healthy controls from individuals with ADHD, individuals with SUD, and individuals with comorbid ADHD and SUD [57]. Since no significant group difference was found in Timing, which differentiates between motor-speed difficulties and inattention [58], we propose that the Attention performance is the one responsible for the disparity between the groups. These results lend further support to the notion that most CPT tasks require multiple cognitive abilities [58]. Therefore, an integration of CPT indexes may better reflect the complexity and heterogeneity of ADHD etiology and clinical manifestations, especially when combined with complex comorbidities. Specifically, using the MOXO-CPT, we found that the impulsivity surpassed the other indexes, and was the most potent risk factor for SUD. This finding supports studies suggesting that impulsivity is an important trait of risk behavior, and plays a major role in SUD [59-61] and SUD vulnerability. However, it should be taken into account that ADHD and SUD have complicated and bi-directional relationships compounding and maintaining the symptoms of each other [62]. Due to this relationship, ADHD symptoms can not only predispose SUD, but can be adversely be affected by SUD [4]. Thus, the cross-sectional design in this study impedes any conclusions concerning the causal relationship.

Indeed, in addition to ADHD, our study looked at sensation-seeking behavior as a trait of risk-taking behavior [16]. This study validates previous findings of higher sensationseeking behavior in individuals with SUD compared to healthy individuals [18]. From 
a sociological perspective, sensation-seeking is an individual interpersonal trait that is the result of reciprocal and reinforcing social influences, implying that the social environment has the ability to limit the negative outcomes of sensation-seeking behavior [63]. Neurophysiologically, sensation-seeking operates under the same neural structures involved in the reward system [64]. Thus, the risky nature of SUD, which meets the desire for sensation-seeking by providing the necessary stimulation [17], may indicate that the sensation-seeking profile we found is a SUD consequence.

Interestingly, Yalachkov, Kasiser, and Naumer (2010) [31] proposed a model describing the way that sensory processing might be involved in addiction mechanisms by stimulating the reward system. According to this model, cue exposure can elicit activations of the sensory and motor representations, which, in turn, activate the reward system, and contribute to an increased likelihood of relapse. As individuals with SMD are characterized by alertness to environmental stimuli, as evidenced by their EEG pattern of response [65], it could be suggested that, in individuals with SMD, a stronger response to environmental stimuli of substance-related cues may be generated. Although the mechanisms governing SMD and the reward systems are yet inconclusive, Borges et al. (2017) found that sensory imbalance was implicated in a decreased resilience to psychoactive substance use. Of note, though balanced sensory processing improves our ability to respond, learn, detect, discriminate, and recognize information from the environment [66], SMD is a product of sensory imbalance which can lead to difficulties managing maladaptive behaviors [67]. Because of its importance in everyday functioning, it is possible to assume that a dysfunctional sensory system could impact daily information processing [25], and therefore have a detrimental effect on a wide variety of health conditions, including SUD. Importantly, the role of the sensory system has been neglected in SUD research [31], leaving a gap in knowledge.

A different perspective suggests the self-medication hypothesis (SMH) [68] explaining the high incidence of SMD in SUD [32]. Namely, a psychoactive substance is used as a coping mechanism for minimizing or avoiding emotional suffering [68-70]. Specifically, since the SMD manifestations include pain [71,72] anxiety [40,73,74], psychological distress [75], negative affect [76], and depression [40], it could be proposed that individuals with SMD choose substance use as a coping mechanism [32]. However, although the relationship between SMD and SUD is scarcely reported, the SMD profile we found may be a SUD consequence, and not a predisposition.

Importantly, finding SMD with the strongest association to SUD is worthy both clinically and for research. Although, to date, ADHD and sensation-seeking have been well established in the literature as risk factors for SUD [12], we found SMD-SOR to be a stronger risk factor than both of these. The probability risk index this study proposes indicates that for identical scores in the sensation-seeking and MOXO-CPT-Impulsivity measures, the presence of SMD-SOR significantly increases the likelihood of SUD. To our knowledge, this is a novel approach not previously explored in SUD. These findings are in line with previous reports suggesting SMD as a predisposing factor serving as a risk factor for other health conditions $[77,78]$. Our findings contribute significantly for the better understanding of SUD, as well as suggesting a new perspective for both prevention and rehabilitation as part of the broader SUD treatment.

\section{Limitations}

Some limitations should be considered, including data collection from a single TC, which could limit the generalization of the results. The unequal sex distribution, though similar to other studies [79], may interfere with generalizability to the female population. In addition, no standard cognitive assessment was performed. Finally, most of the outcome measures were based on self-reporting, which may be subject to response biases. Future studies require using a larger sample size consisting of various TCs with a larger female cohort, such that sensory modulation sub-types could be studied in relation to the preferred psychoactive substance consumed. 


\section{Conclusions}

Our results emphasize that SMD has the strongest relation to SUD, exceeding that of ADHD. Moreover, our study emphasizes that SMD significantly increases the likelihood of SUD. These findings highlight the need to address sensory modulation in the course of SUD rehabilitation, in addition to attention, impulsivity, and hyperactivity. Therefore, our findings may suggest a new perspective for both prevention and rehabilitation as part of the broader SUD treatment.

Author Contributions: Conceptualization, N.A., S.P., I.B., H.M. and T.B.-S.; methodology, N.A., S.P., I.B., H.M. and T.B.-S.; software, N.A.; validation, N.A., S.P. and T.B.-S.; formal analysis, N.A.; investigation, N.A., S.P. and T.B.-S.; resources, N.A., S.P. and T.B.-S.; data curation, N.A., S.P. and T.B.-S.; writing-original draft preparation N.A., S.P., I.B., H.M. and T.B.-S.; writing-review and editing, N.A., S.P. and T.B.-S.; supervision, S.P. and T.B.-S.; project administration, N.A.; funding acquisition, T.B.-S. All authors have read and agreed to the published version of the manuscript.

Funding: This work was supported by the National Insurance Institute of Israel (grant number 16541910) and Israel Authority for Prevention of Violence, Alcohol and Drug Abuse (grant number 01020036).

Institutional Review Board Statement: The study was conducted according to the guidelines of the Declaration of Helsinki, and approved by the Institutional Review Board (or Ethics Committee) of the School of Health Professions, Sackler Faculty of Medicine, Tel Aviv University (11002976_20160720).

Informed Consent Statement: Informed consent was obtained from all subjects involved in the study.

Data Availability Statement: The data that support the findings of this study are available from the corresponding author, upon reasonable request.

Acknowledgments: We wish to thank the National Insurance Institute of Israel and the Israel Authority for Violence, Alcohol and Drug Abuse Prevention for their support in this study. We also extend our gratitude to the participants and the multidisciplinary team of the Therapeutic Community. We thank Lisa Deutsch for her statistical consultation.

Conflicts of Interest: The authors declare no conflict of interest.

\section{References}

1. Wilens, T.E.; Kaminski, T.A. The Co-Occurrence of ADHD and Substance Use Disorders. Psychiatr. Ann. 2018, 48, 328-332. [CrossRef]

2. van de Glind, G.; Konstenius, M.; Koeter, M.W.J.; van Emmerik-van Oortmerssen, K.; Carpentier, P.J.; Kaye, S.; Degenhardt, L.; Skutle, A.; Franck, J.; Bu, E.T.; et al. Variability in the Prevalence of Adult ADHD in Treatment Seeking Substance Use Disorder Patients: Results from an International Multi-Center Study Exploring DSM-IV and DSM-5 Criteria. Drug Alcohol Depend. 2014, 134, 158-166. [CrossRef] [PubMed]

3. Zulauf, C.A.; Sprich, S.E.; Safren, S.A.; Wilens, T.E. The Complicated Relationship between Attention Deficit/Hyperactivity Disorder and Substance Use Disorders. Curr. Psychiatry Rep. 2014, 16, 436. [CrossRef] [PubMed]

4. Fluyau, D.; Revadigar, N.; Pierre, C.G. Systematic Review and Meta-Analysis: Treatment of Substance Use Disorder in Attention Deficit Hyperactivity Disorder. Am. J. Addict. 2021, 30, 110-121. [CrossRef]

5. Yule, A.M.; Martelon, M.; Faraone, S.V.; Carrellas, N.; Wilens, T.E.; Biederman, J. Examining the Association between Attention de Fi Cit Hyperactivity Disorder and Substance Use Disorders: A Familial Risk Analysis. J. Psychiatr. Res. 2017, 85, 49-55. [CrossRef]

6. American Psychiatric Association. Diagnostic and Statistical Manual of Mental Disorders; American Psychiatric Publishing: Arlington, VA, USA, 2013.

7. Fayyad, J.; Sampson, N.A.; Hwang, I.; Adamowski, T.; Aguilar-Gaxiola, S.; Al-Hamzawi, A.; Andrade, L.H.; Borges, G.; de Girolamo, G.; Florescu, S. The Descriptive Epidemiology of DSM-IV Adult ADHD in the World Health Organization World Mental Health Surveys. Atten. Defic. Hyperact. 2017, 9, 47-65. [CrossRef]

8. Kuriyan, A.B.; Pelham, W.E.; Gnagy, E.M.; Sibley, M.H.; Babinski, D.E.; Walther, C.; Cheong, J.; Yu, J.; Kent, K.M. Young Adult Educational and Vocational Outcomes of Children Diagnosed with ADHD. J. Abnorm. Child Psychol. 2013, 41, 27-41. [CrossRef]

9. Scheres, A.; Solanto, M.V. Do Adhd Symptoms, Executive Function, and Study Strategies Predict Temporal Reward Discounting in College Students with Varying Levels of Adhd Symptoms? A Pilot Study. Brain Sci. 2021, 11, 181. [CrossRef]

10. van Emmerik-van Oortmerssen, K.; van de Glind, G.; van den Brink, W.; Smit, F.; Crunelle, C.L.; Swets, M.; Schoevers, R.A. Prevalence of Attention-Deficit Hyperactivity Disorder in Substance Use Disorder Patients: A Meta-Analysis and Meta-Regression Analysis. Drug Alcohol Depend. 2012, 122, 11-19. [CrossRef] 
11. Levy, S.; Katusic, S.K.; Colligan, R.C.; Weaver, A.L.; Killian, J.M.; Voigt, R.G.; Barbaresi, W.J. Childhood ADHD and Risk for Substance Dependence in Adulthood: A Longitudinal, Population-Based Study. PLoS ONE 2014, 9, e105640. [CrossRef]

12. Wilens, T.E.; Martelon, M.; Gagan, J.; Bateman, C.; Ronna, F.; Petty, C.; Biederman, J. Does ADHD Predict Substance-Use of Young Adults with ADHD. JAAC 2011, 50, 543-553. [CrossRef]

13. Wiklund, J.; Yu, W.; Tucker, R.; Marino, L.D. ADHD, impulsivity and entrepreneurship. J. Bus. Ventur. 2017, 32, 627-656. [CrossRef]

14. Jensen, M.; Chassin, L.; Gonzales, N.A. Neighborhood Moderation of Sensation Seeking Effects on Adolescent Substance Use Initiation. J. Youth Adolesc. 2017, 1953-1967. [CrossRef]

15. Zuckerman, M. Behavioral Expressions and Biosocial Bases of Sensation Seeking; Cambridge University Press: New York, NY, USA; Cambridge University Press: Cambridge, UK, 1994.

16. Vreeker, A.; van der Burg, B.G.; van Laar, M.; Brunt, T.M. Characterizing Users of New Psychoactive Substances Using Psychometric Scales for Risk-Related Behavior. Addict. Behav. 2017, 70, 72-78. [CrossRef] [PubMed]

17. Hoyle, R.H.; Stephenson, M.T.; Palmgreen, P.; Pugzles, E.; Donohew, R.L. Reliability and Validity of a Brief Measure of Sensation Seeking. Personal. Individ. Differ. 2002, 32, 401-414. [CrossRef]

18. Malmberg, M.; Overbeek, G.; Monshouwer, K.; Lammers, J.; Vollebergh, W.A.; Engels, R.C. Substance Use Risk Profiles and Associations with Early Substance Use in Adolescence. J. Behav. Med. 2010, 33, 474-485. [CrossRef] [PubMed]

19. Moggi, F.; Schorno, D.; Soravia, L.M.; Mohler-Kuo, M.; Estévez-Lamorte, N.; Studer, J.; Gmel, G. Screened Attention Deficit/Hyperactivity Disorder as a Predictor of Substance Use Initiation and Escalation in Early Adulthood and the Role of Self-Reported Conduct Disorder and Sensation Seeking: A 5-Year Longitudinal Study with Young Adult Swiss Men. Eur. Addict. Res. 2020, 26, 233-244. [CrossRef]

20. Kalig-Amir, M.; Berger, I.; Rigbi, A.; Bar-shalita, T. An Exploratory Study of Parent-Child Association in Sensory Modulation Disorder Involving ADHD-Related Symptoms. Pediatr. Res. 2019, 86, 221-226. [CrossRef]

21. Mazor-Karsenty, T.; Parush, S.; Bonneh, Y.; Shalev, L. Research in Developmental Disabilities Comparing the Executive Attention of Adult Females with ADHD to That of Females with Sensory Modulation Disorder (SMD) under Aversive and Non-Aversive Auditory Conditions. Res. Dev. Disabil. 2015, 37, 17-30. [CrossRef]

22. Miller, L.J.; Nielsen, D.M.; Schoen, S.A. Attention Deficit Hyperactivity Disorder and Sensory Modulation Disorder: A Comparison of Behavior and Physiology. Res. Dev. Disabil. 2012, 33, 804-818. [CrossRef]

23. Delgado-Lobete, L.; Pértega-Díaz, S.; Santos-del-Riego, S.; Montes-Montes, R. Sensory Processing Patterns in Developmental Coordination Disorder, Attention Deficit Hyperactivity Disorder and Typical Development. Res. Dev. Disabil. 2020, 100, 103608. [CrossRef] [PubMed]

24. Interdisciplinary Council on Developmental and Learning Disorders (ICDL). Diagnostic Manual for Infancy and Early Childhood; ICDL: Bethesda, MD, USA, 2005.

25. Miller, L.J.; Anzalone, M.E.; Lane, S.J.; Cermak, S.A.; Osten, E.T. Concept Evolution in Sensory Integration: A Proposed Nosology for Diagnosis. Am. J. Occup. Ther. 2007, 61, 135-140. [CrossRef] [PubMed]

26. Zero to Three. Diagnostic Classification: 0-3R: Diagnostic Classification of Mental Health and Developmental Disorders of Infancy and Early Childhood; National Center for Clinical: Washington, DC, USA, 2005.

27. Kinnealey, M.; Oliver, B.; Wilbarger, P. A Phenomenological Study of Sensory Defensiveness in Adults. Am. J. Occup. Ther. 1995, 49, 444-451. [CrossRef] [PubMed]

28. Bar-Shalita, T.; Deutsch, L.; Honigman, L.; Weissman-Fogel, I. Ecological Aspects of Pain in Sensory Modulation Disorder. Res. Dev. Disabil. 2015, 45-46, 157-167. [CrossRef] [PubMed]

29. Weissman-Fogel, I.; Granovsky, Y.; Bar-Shalita, T. Sensory Over-Responsiveness among Healthy Subjects Is Associated with a Pronociceptive State. Pain Pract. 2018, 18, 473-486. [CrossRef]

30. Ryu, J.; Bar-Shalita, T.; Granovsky, Y.; Weissman-Fogel, I.; Torres, E.B. Personalized Biometrics of Physical Pain Agree with Psychophysics by Participants with Sensory over Responsivity. J. Pers. Med. 2021, 11, 93. [CrossRef]

31. Yalachkov, Y.; Kaiser, J.; Naumer, M.J. Sensory and Motor Aspects of Addiction. Behav. Brain Res. 2010, 207, 215-222. [CrossRef]

32. Assayag, N.; Bonneh, Y.; Parush, S.; Mell, H.; Neeman Kaplan, R.; Bar-Shalita, T. Perceived Sensitivity to Pain and Responsiveness to Non-Noxious Sensation in Substance Use Disorder. Pain Med. 2019, 21, 1902-1912. [CrossRef]

33. Bashapoor, S.; Hosseini-kiasari, S.T.; Daneshvar, S.; Kazemi-Taskooh, Z. Comparing Sensory Information Processing and Alexithymia between People with Substance Dependency and Normal. Addict. Health 2015, 7, 174.

34. Borges, J.M.; Antonio, J.; Marzo, J.C. Relationship Between Sensory Processing, Relationship between Sensory Processing, Resilience, Attitudes and Drug use in Portuguese Adults. Paidéia (Ribeirão Preto) 2017, 27, 255-262. [CrossRef]

35. Engel-Yeger, B. Sensory Processing Disorders among Substance Dependents. Cad. Bras. Ter. Ocup. 2014, 22, 111-118. [CrossRef]

36. Kelly, J.; Meredith, P.J.; Taylor, M.; Morphett, A.; Wilson, H. Substances and Your Senses: The Sensory Patterns of Young People within an Alcohol and Drug Treatment Service. Subst. Abus. 2021, 42, 998-1006. [CrossRef] [PubMed]

37. Yochman, A.; Alon-Beery, O.; Sribman, A.; Parush, S. Differential Diagnosis of Sensory Modulation Disorder (SMD) and Attention Deficit Hyperactivity Disorder (ADHD): Participation, Sensation, and Attention. Front. Hum. Neurosci. 2013, 7, 862. [CrossRef]

38. Bar-Shalita, T.; Vatine, J.J.; Parush, S. Sensory Modulation Disorder: A Risk Factor for Participation in Daily Life Activities. Dev. Med. Child Neurol. 2008, 50, 932-937. [CrossRef] [PubMed] 
39. Dunn, W.; Little, L.; Dean, E.; Robertson, S.; Evans, B. The State of the Science on Sensory Factors and Their Impact on Daily Life for Children: A Scoping Review. Particip. Health 2016, 6 (Suppl. 2), 3S-26S. [CrossRef] [PubMed]

40. Kinnealey, M.; Koenig, K.P.; Smith, S. Relationships between Sensory Modulation and Social Supports and Health-Related Quality of Life. Am. J. Occup. Ther. 2011, 65, 320-327. [CrossRef]

41. Bunt, G.C.; Muehlbach, B.; Moed, C.O. The Therapeutic Community: An International Perspective. Subst. Abus. 2008, 29 , 81-87. [CrossRef]

42. Verdejo-García, A.; Pérez-García, M. Profile of Executive Deficits in Cocaine and Heroin Polysubstance Users: Common and Differential Effects on Separate Executive Components. Psychopharmacology 2007, 190, 517-530. [CrossRef]

43. Dickerson, A.E. Securing sample for effective research across research designs. In Research in Occupational Therapy: Methods of Inquiry for Enhancing Practice; Kielhofner, G., Ed.; Davis Company: Philadelphia, PA, USA, 2006; pp. 515-529.

44. Berger, I.; Goldzweig, G. Objective Measures of Attention-Deficit/Hyperactivity Disorder: A Pilot Study. Isr. Med. Assoc. J. 2010, $12,531-535$.

45. Berger, I.; Cassuto, H. The Effect of Environmental Distractors Incorporation into a CPT on Sustained Attention and ADHD Diagnosis among Adolescents. J. Neurosci. Methods 2014, 222, 62-68. [CrossRef]

46. Kessler, R.C.; Adler, L.; Ames, M.; Demler, O.; Faraone, S.; Hiripi, E.V.A.; Howes, M.J.; Jin, R.; Secnik, K.; Spencer, T. The World Health Organization Adult ADHD Self-Report Scale (ASRS): A Short Screening Scale for Use in the General Population. Psychol. Med. 2005, 35, 245-256. [CrossRef] [PubMed]

47. Kessler, R.C.; Adler, L.A.; Gruber, M.J.; Sarawate, C.A.; Spencer, T.; Brunt, D.L.V.A.N. Validity of the World Health Organization Adult ADHD Self-Report Scale (ASRS) Screener in a Representative Sample of Health Plan Members. Int. J. Methods Psychiatr. Res. 2007, 16, 52-65. [CrossRef]

48. Van De Glind, G.; Van Emmerik-van Oortmerssen, K.; Carpentier, P.J.; Levin, F.R.; Koeter, M.W.; Barta, C.; Kaye, S.; Skutle, A.; Franck, J.; Konstenius, M. The International ADHD in Substance Use Disorders Prevalence (IASP) Study: Background, Methods and Study Population. Int. J. Methods Psychiatr. Res. 2013, 22, 232-244. [CrossRef] [PubMed]

49. Ustun, B.; Adler, L.A.; Rudin, C.; Faraone, S.V.; Spencer, T.J.; Berglund, P.; Gruber, M.J.; Kessler, R.C. The World Health Organization Adult Attention-Deficit/Hyperactivity Disorder Self-Report Screening Scale for DSM-5. JAMA Psychiatry 2017, 74, 520-526. [CrossRef] [PubMed]

50. Adler, L.A.; Spencer, T.; Stephen, F.; Kessler, R.C.; Howes, M.J.; Biederman, J.; Secnik, K. Validity of Pilot Adult ADHD Self-Report Scale (ASRS) to Rate Adult ADHD Symptoms. Ann. Clin. Psychiatry 2006, 18, 145-148. [CrossRef]

51. Matza, L.S.; Van Brunt, D.L.; Cates, C.; Murray, L.T. Test-Retest Reliability of Two Patient-Report Measures for Use in Adults With ADHD. J. Atten. Disord. 2011, 15, 557-563. [CrossRef]

52. Bar-Shalita, T.; Seltzer, Z.; Vatine, J.; Yochman, A.; Parush, S. Development and Psychometric Properties of the Sensory Responsiveness Questionnaire (SRQ). Disabil. Rehabil. 2009, 31, 189-201. [CrossRef]

53. Shlosberg, D.; Amit, B.H.; Zalsman, G.; Krivoy, A.; Mell, H.; Lev-Ran, S.; Shoval, G. Cognitive Impairments in Abstinent Male Residents of a Therapeutic Community for Substance-Use Disorders: A Five-Year Retrospective Study. Subst. Use Misuse 2019, 54, 538-548. [CrossRef]

54. Van De Glind, G.; Brynte, C.; Skutle, A.; Kaye, S.; Konstenius, M.; Levin, F.; Mathys, F.; Demetrovics, Z.; Moggi, F.; Ramos-Quiroga, J.A.; et al. The International Collaboration on ADHD and Substance Abuse (ICASA): Mission, Results, and Future Activities. Eur. Addict. Res. 2020, 26, 173-178. [CrossRef]

55. Hagen, E.; Erga, A.H.; Nesvåg, S.M.; Mckay, J.R.; Lundervold, A.J. One-Year Abstinence Improves ADHD Symptoms among Patients with Polysubstance Use Disorder. Addict. Behav. Rep. 2017, 6, 96-101. [CrossRef]

56. Farhoodi, F.; Rostami, R.; Abdolmanafi, A.; Amiri, M. A Study and Comparison of the Symptoms of Attention Deficit Hyperactivity Disorder (ADHD) among Patients with Substance Use Disorder and Normal People. Procedia Soc. Behav. Sci. 2010, 5, 892-895. [CrossRef]

57. Slobodin, O.; Blankers, M.; Kapitány-Fövény, M.; Kaye, S.; Berger, I.; Johnson, B.; Demetrovics, Z.; Van Den Brink, W.; Van De Glind, G. Differential Diagnosis in Patients with Substance Use Disorder and/or Attention-Deficit/Hyperactivity Disorder Using Continuous Performance Test. Eur. Addict. Res. 2020, 26, 151-162. [CrossRef] [PubMed]

58. Berger, I.; Slobodin, O.; Cassuto, H. Usefulness and Validity of Continuous Performance Tests in the Diagnosis of Attention-De Fi Cit Hyperactivity Disorder Children. Arch. Clin. Neuropsychol. 2017, 32, 81-93. [CrossRef]

59. Loree, A.M.; Lundahl, L.H.; Ledgerwood, D.M. Impulsivity as a Predictor of Treatment Outcome in Substance Use Disorders: Review and Synthesis. Drug Alcohol Rev. 2015, 34, 119-134. [CrossRef] [PubMed]

60. Stevens, L.; Verdejo-garcía, A.; Goudriaan, A.E.; Roeyers, H.; Dom, G.; Vanderplasschen, W. Impulsivity as a Vulnerability Factor for Poor Addiction Treatment Outcomes: A Review of Neurocognitive Fi Ndings among Individuals with Substance Use Disorders. J. Subst. Abuse Treat. 2014, 47, 58-72. [CrossRef] [PubMed]

61. Verdejo-Garc1, A.; Lawrence, A.J.; Clark, L. Impulsivity as a Vulnerability Marker for Substance-Use Disorders: Review of Findings from High-Risk Research, Problem Gamblers and Genetic Association Studies. Neurosci. Biobehav. Rev. 2008, 32, 777-810. [CrossRef] [PubMed]

62. Young, J.T.; Bellgrove, M.A.; Arunogiri, S. Assessment of Attention-Deficit Hyperactivity Disorder in People with Substance Use Disorder: Another Case of What Gets Measured Gets Done. Aust. N. Z. J. Psychiatry 2021, 55, 744-746. [CrossRef] 
63. Kaynak, Ö.; Meyers, K.; Caldeira, K.M.; Vincent, K.B.; Winters, K.C.; Arria, A.M. Addictive Behaviors Relationships among Parental Monitoring and Sensation Seeking on the Development of Substance Use Disorder among College Students. Addict. Behav. 2013, 38, 1457-1463. [CrossRef]

64. Bardo, M.T.; Donohew, R.L.; Harrington, N.G. Psychobiiology of Novelty Seeking and Drug Seeking Behavior. Behav. Brain Res. 1996, 77, 23-43. [CrossRef]

65. Granovsky, Y.; Weissman-Fogel, I.; Bar-Shalita, T. Resting-State EEG in Individuals with Sensory over-Responsivity: An Exploratory Study. Am. J. Occup. Ther. 2018, 73. [CrossRef]

66. Chandrasekaran, C. ScienceDirect Computational Principles and Models of Multisensory Integration. Curr. Opin. Neurobiol. 2017, 43, 25-34. [CrossRef]

67. Warner, E.; Koomar, J.; Lary, B.; Cook, A. Can the Body Change the Score? Application of Sensory Modulation Principles in the Treatment of Traumatized Adolescents in Residential Settings. J. Fam. Violence 2013, 28, 729-738. [CrossRef]

68. McKernan, L.C.; Nash, M.R.; Gottdiener, W.H.; Anderson, S.E.; Lambert, W.E.; Carr, E.R. Further Evidence of Self-Medication: Personality Factors Influencing Drug Choice in Substance Use Disorders. Psychiatry 2015, 43, 243-275. [CrossRef] [PubMed]

69. Alexander, A.C.; Ward, K.D. Understanding Postdisaster Substance Use and Psychological Distress Using Concepts from the Self-Medication Hypothesis and Social Cognitive Theory. J. Psychoact. Drugs 2018, 50, 177-186. [CrossRef] [PubMed]

70. Khantzian, E.J. Understanding Addictive Vulnerability: An Evolving Psychodynamic Perspective. Neuropsychoanalysis 2003, 5, 5-21. [CrossRef]

71. Bar-shalita, T.; Granovsky, Y.; Parush, S.; Weissman-fogel, I. Sensory Modulation Disorder (SMD) and Pain: A New Perspective. Front. Integr. Neurosci. 2019, 13, 27. [CrossRef]

72. Meredith, P.J.; Andrews, N.E.; Thackeray, J.; Bowen, S.; Poll, C.; Strong, J. Can Sensory- and Attachment-Informed Approaches Modify the Perception of Pain? An Experimental Study. Pain Res. Manag. 2021, 2021, 5527261. [CrossRef]

73. Bart, O.; Bar-Shalita, T.; Mansour, H.; Dar, R. Relationships among Sensory Responsiveness, Anxiety, and Ritual Behaviors in Children with and without Atypical Sensory Responsiveness. Phys. Occup. Ther. Pediatr. 2017, 37, 322-331. [CrossRef]

74. Engel-Yeger, B.; Dunn, W. The Relationship between Sensory Processing Difficulties and Anxiety Level of Healthy Adults. Br. J. Occup. Ther. 2011, 74, 210-216. [CrossRef]

75. Bar-Shalita, T.; Cermak, S.A. Atypical Sensory Modulation and Psychological Distress in the General Population. Am. J. Occup. Ther. 2016, 70, 7004250010p1-7004250010p9. [CrossRef]

76. Engel-Yeger, B.; Dunn, W. Exploring the Relationship between Affect and Sensory Processing Patterns in Adults. Br. J. Occup. Ther. 2011, 74, 456-464. [CrossRef]

77. Bar-shalita, T.; Livshitz, A.; Levin-meltz, Y.; Rand, D.; Deutsch, L.; Vatine, J. Sensory Modulation Dysfunction Is Associated with Complex Regional Pain Syndrome. PLoS ONE 2018, 13, e0201354. [CrossRef] [PubMed]

78. Granovsky, Y.; Shor, M.; Shifrin, A.; Sprecher, E.; Yarnitsky, D.; Bar-Shalita, T. Assessment of Responsiveness to Everyday Non-Noxious Stimuli in Pain-Free Migraineurs with versus without Aura. J. Pain 2018, 8, 943-951. [CrossRef] [PubMed]

79. Vergara-Moragues, E.; Verdejo-García, A.; Lozano, O.M.; Santiago-Ramajo, S.; González-Saiz, F.; Betanzos Espinosa, P.; Pérez García, M. Association between Executive Function and Outcome Measure of Treatment in Therapeutic Community among Cocaine Dependent Individuals. J. Subst. Abuse Treat. 2017, 78, 48-55. [CrossRef] 